\title{
COUVE-FLOR CULTIVADA EM SUBSTRATO: MARCHA DE ABSORÇÃO DE MACRONUTRIENTES E MICRONUTRIENTES
}

\author{
Cauliflower cultivated in substrate: progress of absorption of \\ macro and micronutrients
}

\author{
Adriana Ursulino Alves ${ }^{1}$, Renato de Mello Prado ${ }^{2}$, Marcus André Ribeiro Correia', \\ Ancélio Ricardo de Oliveira Gondim ${ }^{1}$, Arthur Bernardes Cecílio Filho ${ }^{3}$, Lucas Sanches Politi ${ }^{4}$
}

\begin{abstract}
RESUMO
Com o objetivo de avaliar marcha de absorção de macro e micronutrientes na couve-flor cultivada em substrato, um experimento foi conduzido em casa de vegetação da UNESP, Campus de Jaboticabal, SP. O delineamento experimental foi de blocos ao acaso, com seis tratamentos e cinco repetições. Os tratamentos foram constituídos pelas épocas de amostragem (20;30; 40; 50; 60 e 70 dias após o transplante). Avaliaram-se os teores e acúmulo dos macro e micronutrientes da parte aérea e raiz. A maior demanda de nutriente aconteceu no período de 60 a 70 (DAT) para macro e micronutrientes. A ordem decrescente dos macronutrientes acumulados pela couve-flor foi: K, N, S, P, Mg e Ca e os micro foi: Fe, Zn, B, Mn e Cu.
\end{abstract}

Termos para indexação: Absorção, nutrição mineral, acúmulo.

\begin{abstract}
With the objective of evaluating the progress of absorption of macro and micronutrients in cauliflower cultivated in substrate, an experiment was conducted in a greenhouse at the Universidade do Estado de São Paulo, in Jaboticabal, Brazil. The experimental desing used was randomized blocks, with six treatments and five replicates. The treatments comprised times of sampling (20;30; 40; 50; 60 and 70 days after the transplant). The composition and accumulation of the macro and micronutrients of the shoot and root were evaluated. The biggest demand of nutrient happened in the period of 60 to 70 (DAT) for macro and micronutrients. The decreasing order of the macronutrients accumulated by the cauliflower was $\mathrm{K}, \mathrm{N}, \mathrm{S}, \mathrm{P}, \mathrm{Mg}$ and $\mathrm{Ca}$ and for micronutrients Fe, $\mathrm{Zn}, \mathrm{B}$, $\mathrm{Mn}$ and $\mathrm{Cu}$.
\end{abstract}

Index terms: Absorption, mineral nutrition, accumulation.

(Recebido em 16 de junho de 2009 e aprovado em 28 de julho de 2010)

\section{INTRODUÇÃo}

As hortaliças produzidas em ambiente protegido e com tecnologia moderna é o início de uma nova horticultura, mais eficiente e capaz de garantir a continuidade, a competitividade e o crescimento do agronegócio hortícola brasileiro. Como se trata de um sistema de cultivo relativamente recente no Estado de São Paulo, a pesquisa torna-se importante para garantir a expansão desse sistema de produção. Nesse sentido, é conhecido que um dos fatores de produção importante para maximizar a produtividade das hortaliças estaria relacionado ao nutricional. Entretanto, na área de produção de hortaliças em substrato, porém, poucos trabalhos foram realizados, especialmente ligados à nutrição mineral.

A grande maioria dos estudos sobre nutrição mineral de hortaliças em geral atem-se a avaliar a resposta pontual das culturas a um elemento isolado, em condições de cultivo em solo, enquanto os estudos sobre as exigências nutricionais das plantas ao longo do cultivo da hortaliça (marcha de absorção) em sistema de cultivo em recipiente com substrato são incipiente ou inexistente para grupo das hortaliças que constituem culturas aptas a esse tipo de cultivo. Assim, o conhecimento da marcha de absorção e do acúmulo de nutrientes nas diferentes fases de desenvolvimento da planta é importante, porque permite determinar as épocas em que os elementos são mais exigidos e corrigir as deficiências que, porventura, venham a ocorrer durante o desenvolvimento das hortaliças.

$\mathrm{Na}$ literatura, os trabalhos que envolvem nutrição em brássicas, estão polarizados a estudos com nutrientes isolados e em condições de campo. Nesses trabalhos, as culturas respondem significativamente à aplicação dos nutrientes, a exemplo do N em couve-flor (cv. Júlia) (Pizetta et al., 2005), ao Mo para couve-flor (Gupta et al., 1978).

\footnotetext{
1Universidade Estadual Paulista “Júlio de Mesquita Filho"/UNESP - Campus de Jaboticabal - Jaboticabal, SP - adrianaursulino@hotmail.com 'Universidade Estadual Paulista "Júlio de Mesquita Filho"/UNESP - Jaboticabal, SP

3Universidade Estadual Paulista "Júlio de Mesquita Filho"/UNESP - Departamento de Solos e Adubos - Jaboticabal, SP

4Universidade Estadual Paulista "Júlio de Mesquita Filho"/UNESP - Departamento de Produção Vegetal - Jaboticabal, SP
} 
Kuramoto et al. (1981) estudaram a nutrição dos micronutrientes sobre o desenvolvimento de couve-flor e verificaram teores adequados e deficientes, respectivamente, para os micronutrientes (em mg kg-1) de B (66-81 e 14-28); $\mathrm{Cu}$ (10-11 e 10-11); Fe (117-139 e 82-119); Mn (45-69 e 11-13); Mo (0,4-0,8 e 0,1-0,3) e Zn (35-48 e 23-28). Homa et al. (1969), avaliando a curva de crescimento da couve-flor, observaram que se iniciou aos 36 dias, com a expansão das folhas externas, e acentua-se aos 56 dias, com seu desenvolvimento.

A adubação e a nutrição das hortaliças especialmente em recipientes com substrato, é feita pelos produtores de forma empírica, com pouco conhecimento da exigência nutricional ou da época de aplicação dos nutrientes. Diante disso, neste trabalho, objetivou-se estudar a marcha de absorção de macro e micronutrientes em couve-flor.

\section{MATERIAL E MÉTODOS}

O experimento foi realizado em telado com sombrite (50\% de luminosidade) do Departamento de Solos e Adubos, localizado na FCAV - UNESP, Jaboticabal, SP, localizado geograficamente a $21^{\circ} 15^{\prime}$ 22 " de latitude sul e 48 18 ' $58^{\prime}$ " de longitude Oeste, na região Norte do Estado de São Paulo, com precipitação média anual de $1400 \mathrm{~mm}$ e temperatura média anual de $21^{\circ} \mathrm{C}$.

As mudas foram produzidas no Setor de Olericultura e Plantas Aromático-medicinais. em espuma fenólica de 2,5 x 2,5 x 3,8 cm, utilizando-se o híbrido Verona. Após sete dias da emergência, as plântulas foram transplantadas para canais de polipropileno de $5 \mathrm{~cm} \mathrm{de}$ largura com solução nutritiva de Hoagland \& Arnon (1950), em sistema hidropônico tipo "nutrient film technique" (NFT), com recirculação da solução, ficando nessa condição durante uma semana e, logo após esse período, foram transplantas para vasos de $5 \mathrm{dm}^{3}$, preenchidos com substrato Plantmax ${ }^{\circledR}$.

Os tratamentos foram constituídos pelas épocas de amostragem (20;30;40; 50; 60 e 70 dias após o transplante), sob delineamento de blocos ao acaso, com cinco repetições. Nesses períodos foram avaliados a altura, o número de folhas, o diâmetro do caule e a área foliar.

As amostras coletadas, plantas inteiras, foram fracionadas em folhas; caule; raiz e inflorescência, e encaminhados ao Laboratório de Nutrição de Plantas do Departamento de Solos e Adubos da Faculdade de Ciências Agrárias e Veterinária - Campus de Jaboticabal, onde foram submetidas à lavagem com água corrente, solução com detergente ( $3 \mathrm{~mL} / \mathrm{L})$, água deionizada, solução com $\mathrm{HCl}$ a $0,1 \mathrm{M}$ e água destilada e colocadas em estufa com circulação forçada de ar à temperatura de $65^{\circ} \mathrm{C}$ para determinação de massa seca.

Após a secagem, o material foi moído e digerido para determinação dos teores de macro e micronutrientes, conforme Bataglia et al. (1983).

Os dados de teores e acúmulo de macro e micronutrientes das partes da planta foram submetidos à análise de variância, pelo teste $F(p<0,05$ e $p<0,01)$. Se significativo pelo teste $\mathrm{F}$, foram ajustadas a equações de regressão polinomial, com maiores coeficientes de determinação, utilizando-se o programa estatístico SAEG (Ribeiro Júnior, 2001).

\section{RESULTADOS E DISCUSSÃO}

$\mathrm{O}$ acúmulo de $\mathrm{N}$ nas raízes, expresso em g por planta, aumentou ao longo do ciclo da cultura, com maior incremento a partir dos $30 \mathrm{DAT}$, em razão do aumento da MSR, mesmo o teor de $\mathrm{N}$ na raiz, expresso em $\mathrm{g} \mathrm{kg}^{-1}$ diminuindo ao longo do ciclo, com pequena variação a partir dos 50 DAT. O P teve aumento no teor e acúmulo até os 50 e 60 DAT, respectivamente, com maior demanda do nutriente entre os 40 e 50 DAT. O K teve aumento no teor e acúmulo até os 50 e 60 DAT respectivamente, com maior demanda do nutriente entre os 40 e 50 DAT. O teor e acúmulo de $\mathrm{Ca}$ aumentaram até os 50 DAT aproximadamente, com maior demanda do nutriente entre os 40 e 50 DAT (Figura 1).

$\mathrm{O}$ teor e acúmulo de $\mathrm{Mg}$ aumentaram aproximadamente até os 45 e 55 DAT respectivamente, com maior demanda entre os 40 e 50 DAT. O teor e o acúmulo de $\mathrm{S}$ aumentaram aproximadamente até os 45 e 60 DAT, respectivamente, com maior demanda dos 20 aos 30 DAT. Para o B não houve diferença significativa no teor e no acúmulo ao longo do ciclo. $\mathrm{O} \mathrm{Cu}$ apresentou aumento no teor e acúmulo até os 60 DAT, com maior demanda entre 30 e 50 DAT (Figura 1).

$\mathrm{O}$ teor $\mathrm{Fe}$ apresentou comportamento quadrático e o acúmulo linear até o final do ciclo, aos 70 DAT. O teor de Mn não teve diferença significativa nas raízes, com acúmulo crescente até os 60 DAT, em função do aumento da massa seca. Para o $\mathrm{Zn}$ o teor quase que aumentou linearmente e o acúmulo foi crescente até os 70 DAT, com maior demanda dos 40 aos 50 DAT (Figura 1). Para todos os nutrientes, houve incremento no acúmulo ao longo do ciclo, em razão do aumento de massa seca, exceto para o B. Os macronutrientes mais absorvidos pelas raízes em ordem decrescente, foram $\mathrm{K}, \mathrm{N}, \mathrm{P}, \mathrm{S}, \mathrm{Ca}$ e $\mathrm{Mg}$, e os micros foram $\mathrm{Fe}, \mathrm{Zn}, \mathrm{Cu}, \mathrm{Mn}$ e B. 

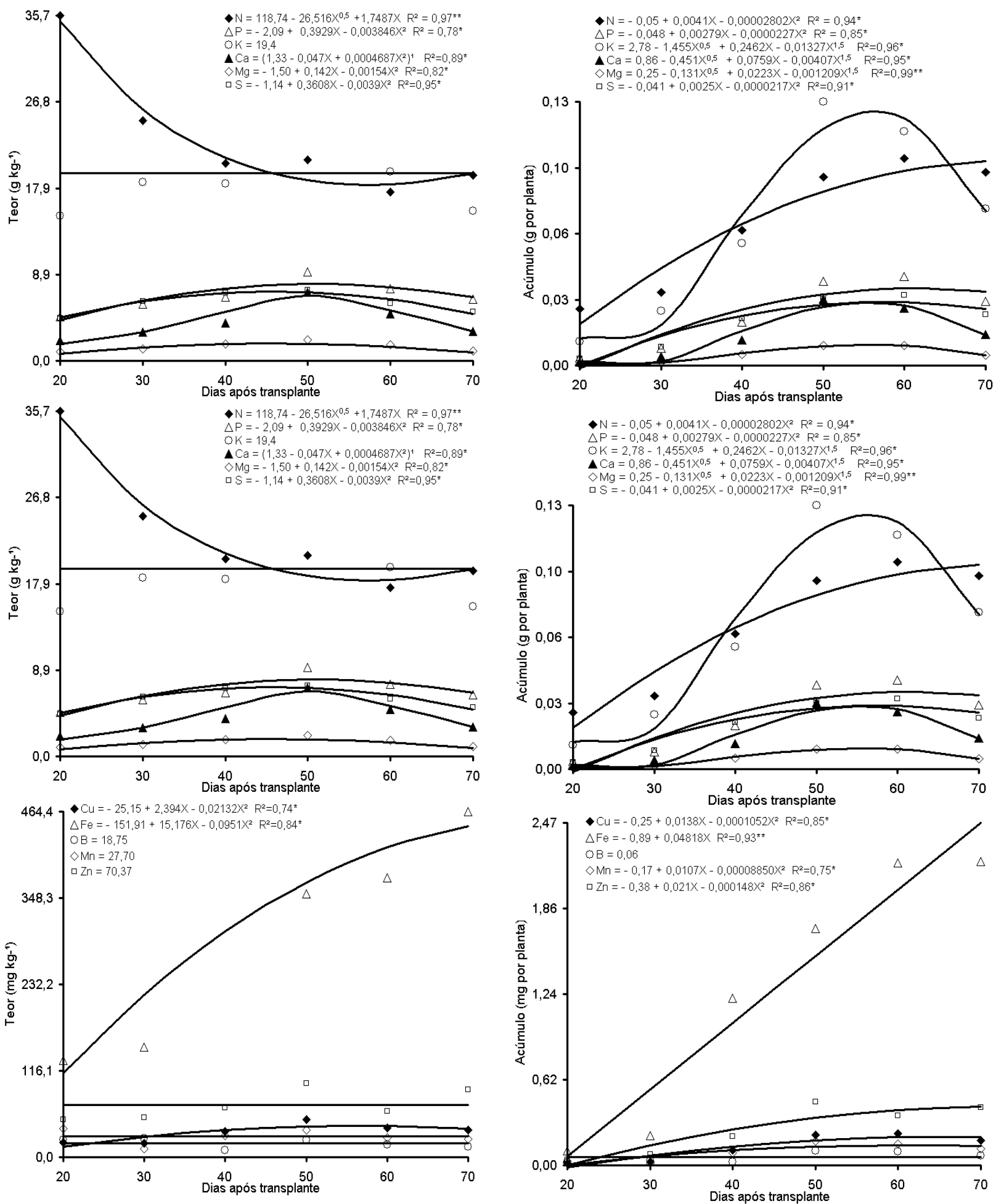

Figura 1 - Teor e acúmulo de macro e de micronutrientes na raiz de couve-flor cultivada em substrato, Híbrido Verona, Jaboticabal-SP, UNESP, 2008. 
$\mathrm{O}$ acúmulo de $\mathrm{N}$ na folha, expresso em g por planta, aumentou ao longo do ciclo até os 70 DAT, com maior incremento dos 40 aos 60 DAT, apesar de o teor do nutriente nas folhas, diminuir ao longo do ciclo. O teor e acúmulo de $\mathrm{P}$ aumentaram até os 50 e 60 DAT, respectivamente, com maior demanda do nutriente dos 20 aos 30 DAT. O teor de K não teve diferença significativa ao longo do ciclo nas folhas, apesar de o acúmulo ter sido crescente até os 60 DAT, com maiores incrementos dos 40 aos 60 DAT, em razão do aumento de massa seca (Figura 2). O teor apresentou comportamento não linear e o acúmulo de $\mathrm{Ca}$ linear ao longo do ciclo, aos 70 DAT. O teor e acúmulo de $\mathrm{Mg}$ aumentaram linearmente ao longo do ciclo, aos 70 DAT.
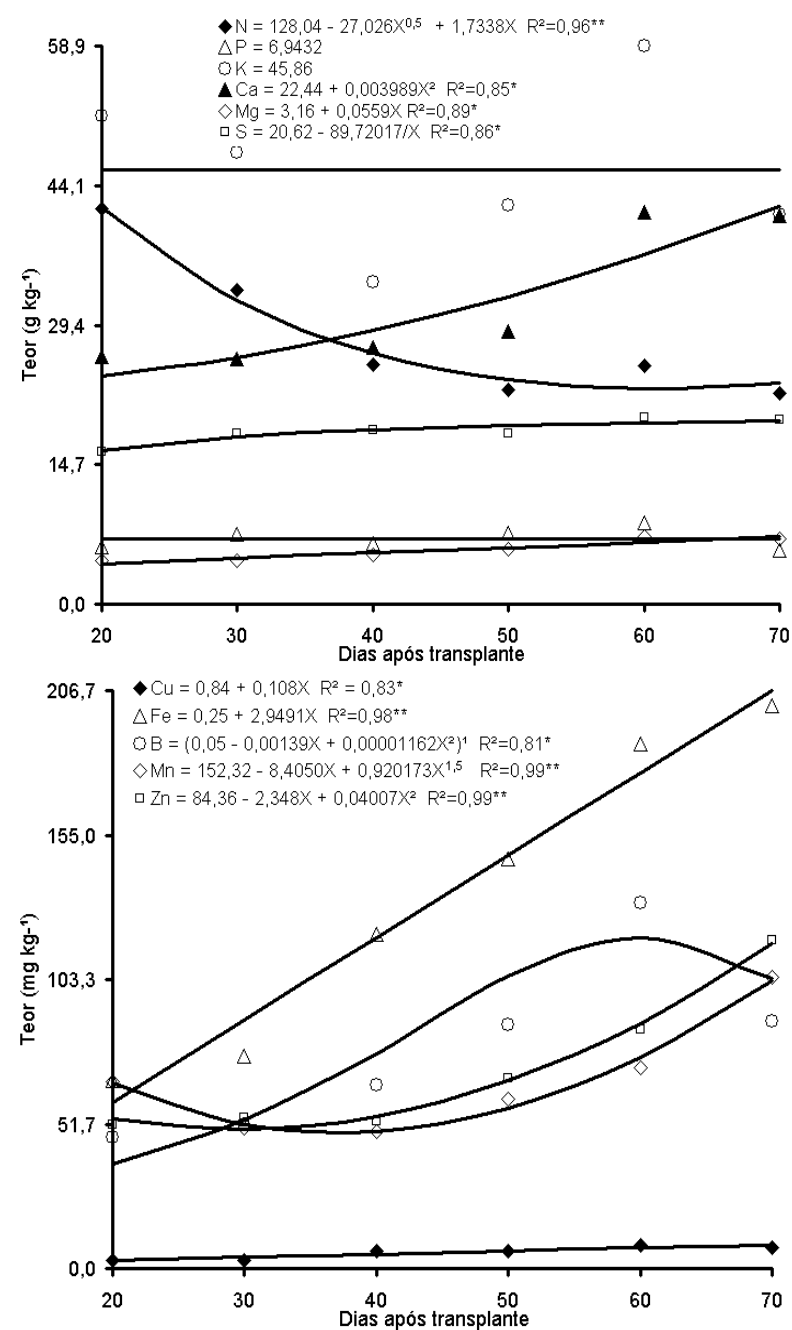

$\mathrm{O}$ teor e acúmulo de $\mathrm{S}$ aumentaram linearmente ao longo do ciclo, apesar de o incremento no teor do nutriente nas folhas ter sido pequeno, com maior demanda dos 50 aos 60 DAT. O teor e acúmulo de B aumentaram até os 60 DAT, com maior demanda dos 50 aos 60 DAT. O teor e acúmulo de $\mathrm{Cu}$ aumentaram quase que linearmente ao longo do ciclo, com maior demanda dos 30 aos 40 DAT (Figura 2). O teor e acúmulo de Fe aumentaram linearmente ao longo do ciclo, 70 DAT. O teor de Mn decresceu até os 40 DAT, a partir desse período passou a aumentar até os 70 DAT, com maior demanda dos 60 aos 70 DAT, e acúmulo crescente quase que linearmente ao longo do ciclo. Para o $\mathrm{Zn}$ houve pequena queda no teor dos 20 aos 30 DAT, quando
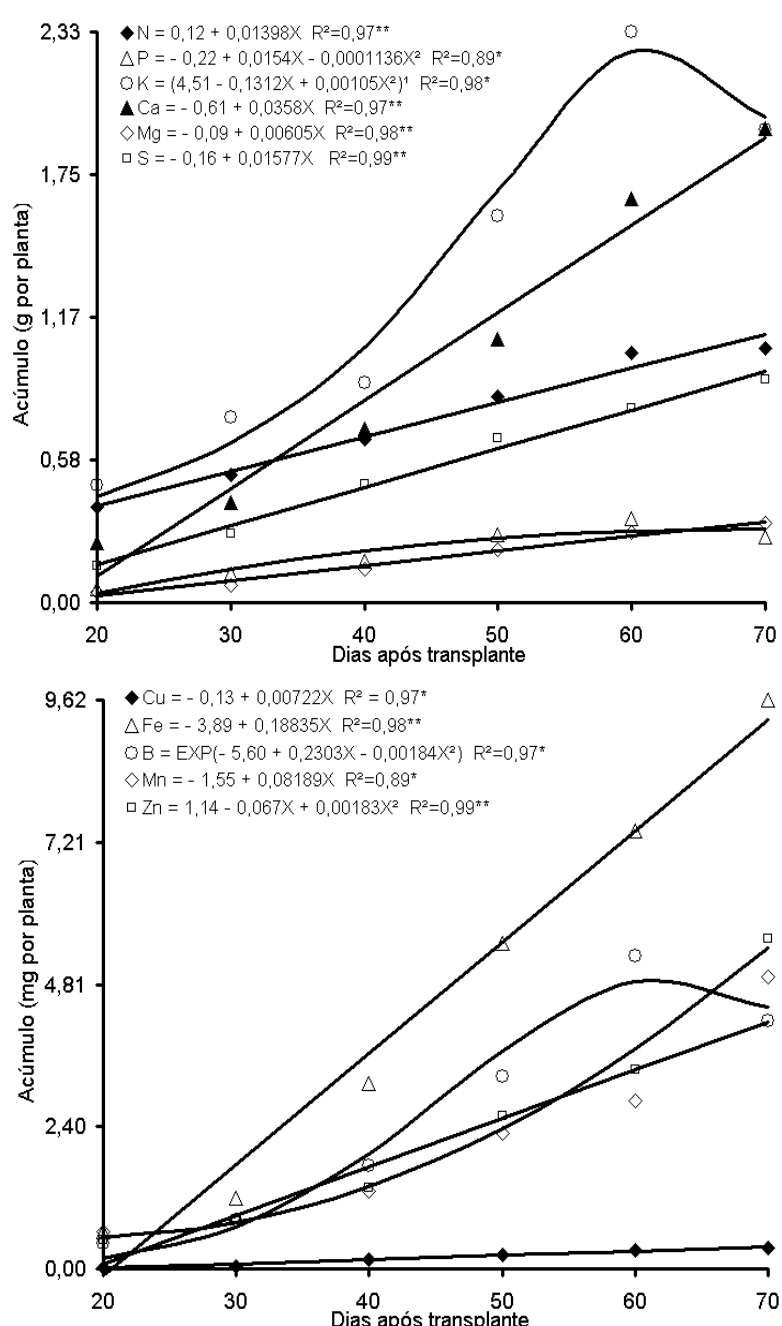

Figura 2 - Teor e acúmulo de macro e micronutrientes na folha de couve-flor cultivada em substrato, cultivar Verona, Jaboticabal-SP, UNESP, 2008.

Ciênc. agrotec., Lavras, v. 35, n. 1, p. 45-55, jan./fev. 2011 
então houve aumento até os 70 DAT, com maior demanda dos 60 aos 70 DAT, e acúmulo crescente durante o ciclo (Figura 2). Para todos os nutrientes houve incremento no acúmulo nas folhas ao longo do ciclo da cultura, em razão do aumento da massa seca. Os micronutrientes mais absorvidos pelas folhas foram em ordem decrescente $\mathrm{Fe}, \mathrm{Mn}, \mathrm{Zn}, \mathrm{B}$ e $\mathrm{Cu}$, e os macros foram $\mathrm{K}$, Ca, N, S, Mg e P.

Resultados obtidos por Vidigal et al. (2002), relatam que o $\mathrm{Fe}$ e o $\mathrm{Mn}$ foram os micronutrientes mais absorvidos pela planta de cebola, seguido do $\mathrm{Cu}, \mathrm{Zn}$ e B. Ao final do ciclo, a cebola extraiu: $1354,66 \mathrm{~g} \mathrm{ha}^{-1} \mathrm{de}$ Fe; 808,07 $\mathrm{g} \mathrm{ha}^{-1}$ de $\mathrm{Mn}$; 376,06 $\mathrm{g} \mathrm{ha}^{-1}$ de Zn; 330,74 $\mathrm{g} \mathrm{ha}^{-1}$ de $\mathrm{Cu}$ e $289,45 \mathrm{~g} \mathrm{ha}^{-1}$ de $\mathrm{B}$.

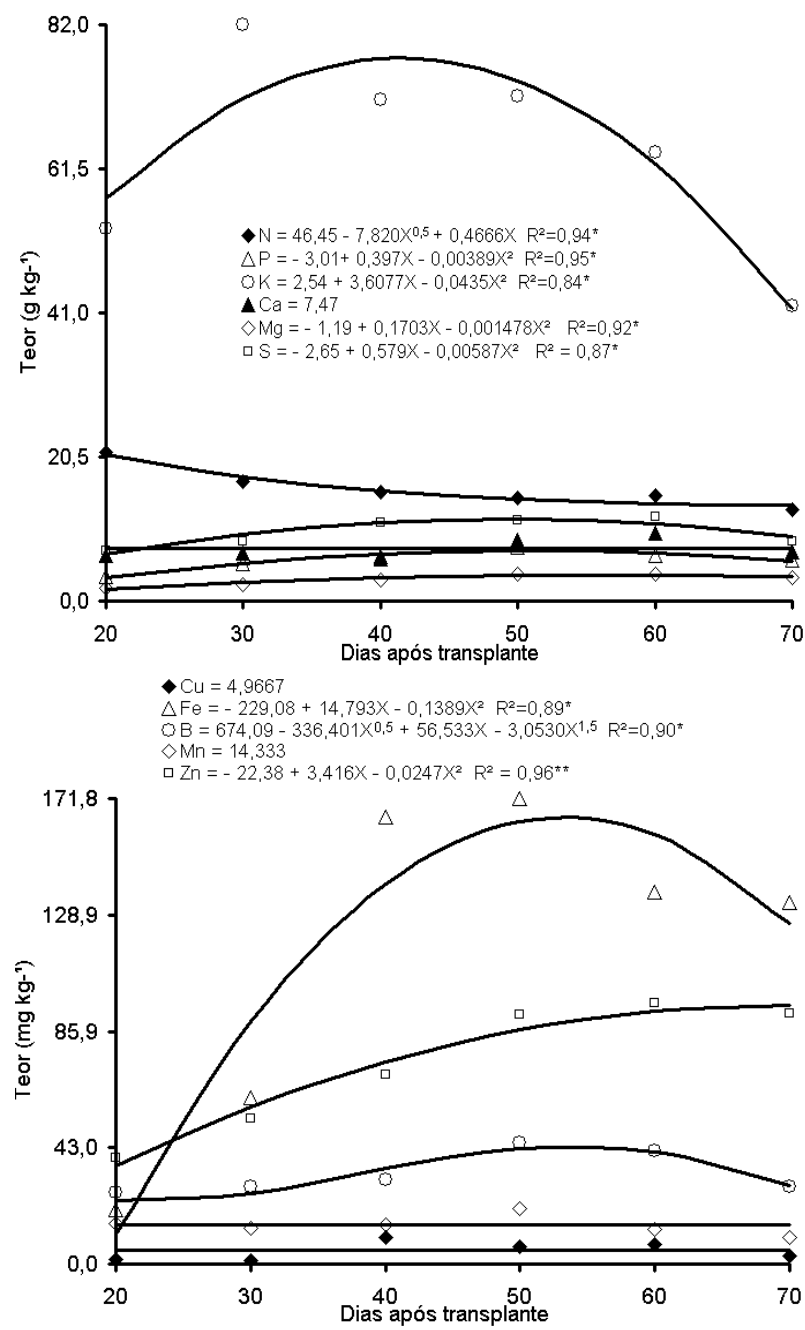

No caule, o $\mathrm{N}$ teve acúmulo crescente até os 70 DAT, com maiores incrementos dos 40 aos 50 DAT, apesar de o teor do nutriente no caule ter diminuído ao longo do ciclo. O teor de $\mathrm{P}$ aumentou até os 50 DAT, quando então diminuiu, tendo maior demanda do nutriente dos 20 aos 30 DAT, e seu acúmulo na planta foi crescente ao longo do ciclo, com maiores incrementos dos 40 aos 50 DAT (Figura 3).

O teor e acúmulo de $\mathrm{K}$ aumentou até os 40 e 60 DAT, respectivamente, diminuído em seguida, com maior demanda do nutriente dos 20 aos 30 DAT. O teor de Ca no caule não variou significativamente ao longo do ciclo, com maior demanda dos 40 aos 50 DAT, e apesar disso o acúmulo foi crescente ao longo do ciclo, com maiores

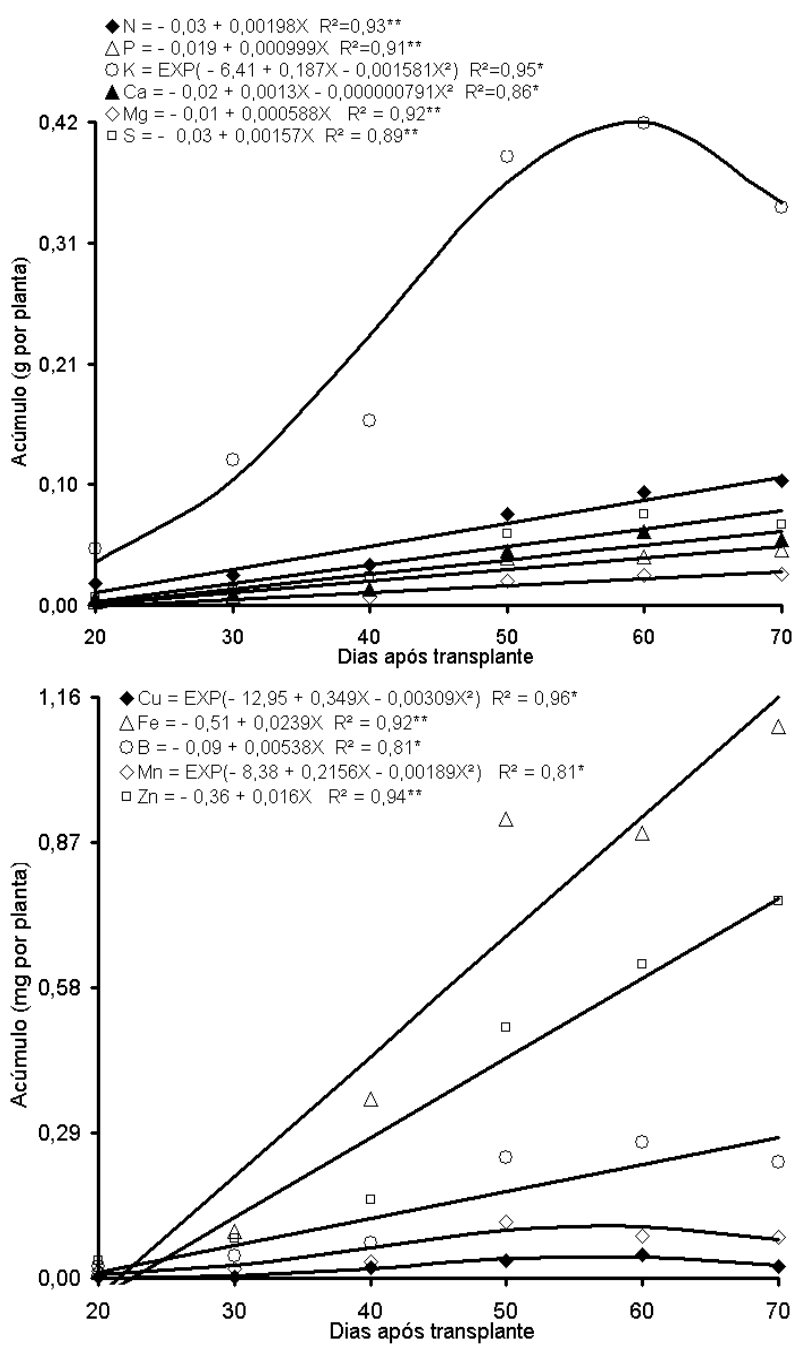

Figura 3 - Teor e acúmulo de macro e micronutrientes no caule de couve-flor cultivado em substrato, cultivar Verona, Jaboticabal-SP, UNESP, 2008. 
incrementos dos 40 aos 50 DAT. O teor de $\mathrm{Mg}$ aumentou até os 60 DAT, diminuindo, posteriormente, com maior demanda do nutriente verificada dos 40 aos 50 DAT, e acúmulo crescente ao longo do ciclo, com maiores incrementos dos 40 aos 50 DAT. O teor de S aumentou até os 50 DAT, quando então decaiu, com maior demanda do nutriente dos 30 aos 40 DAT, e acúmulo crescente ao longo do ciclo, com maiores incrementos dos 40 aos 50 DAT (Figura 3).

Dentre os micronutrientes, o teor de B no caule aumentou até os 50 DAT, decaindo posteriormente, com maior demanda do nutriente dos 40 aos 50 DAT, e acúmulo crescente ao longo do ciclo, com maiores incrementos dos 40 aos 50 DAT. O teor e acúmulo de $\mathrm{Cu}$ aumentou até aproximadamente os 50 e 60 DAT, respectivamente, decaindo em seguida, com maior demanda do nutriente $\mathrm{e}$ também maiores incrementos no acúmulo dos 30 aos 40 DAT (Figura 3).

O teor de Fe aumentou até os 50 DAT, decaindo posteriormente, com maior demanda do nutriente dos 30 aos 40 DAT, e acúmulo crescente ao longo do ciclo, com maiores incrementos dos 40 aos 50 DAT. O teor de Mn no caule não variou significativamente ao longo do ciclo, apresentando maior demanda do nutriente dos 40 aos 50 DAT, e apesar disso, acúmulo crescente até os 55 dias aproximadamente, decaindo, em seguida, com maiores incrementos dos 40 aos 50 DAT. O teor e acúmulo de $\mathrm{Zn}$ no caule aumentaram ao longo do ciclo, tendo maior demanda do nutriente e maiores incrementos no acúmulo dos 40 aos 50 DAT (Figura 3). Para todos os nutrientes, houve incremento no acúmulo no caule ao longo do ciclo da cultura, em razão do aumento da massa seca.

$\mathrm{Na}$ inflorescência, o acúmulo de $\mathrm{N}$ foi crescente ao longo do ciclo da cultura, com maiores incrementos dos 50 aos 60 DAT, mesmo com diminuição do teor após 55 DAT, decorrente da diluição sofrida no teor do nutriente na planta com o grande aumento de massa seca, sendo assim, os valores de acúmulo melhor expressam a necessidade do nutriente pela planta, como já explicado anteriormente. $\mathrm{O}$ acúmulo de $\mathrm{P}$, assim como o $\mathrm{N}$, foi crescente ao longo do ciclo, indicando que houve absorção do nutriente durante o ciclo todo, com maiores incrementos dos 50 aos 60 DAT, mesmo com diminuição do teor na planta após os 55 DAT, aproximadamente (Figura 4).

$\mathrm{O}$ acúmulo de $\mathrm{K}$ também foi crescente ao longo do ciclo, com maiores incrementos dos 50 aos 60 DAT, apesar do teor diminuir a partir dos 60 DAT. O acúmulo de Ca foi crescente até os 60 DAT, diminuindo logo depois, com maiores incrementos dos 50 aos 60 DAT, e teor diminuindo após os $55 \mathrm{DAT}$, aproximadamente. $\mathrm{O}$ acúmulo de $\mathrm{Mg}$ foi crescente durante o ciclo, com maiores incrementos dos 50 aos 60 DAT, apesar do teor diminuir após os 55 DAT, aproximadamente. O acúmulo de $\mathrm{S}$ também foi crescente ao longo do ciclo, com maiores incrementos dos 50 aos 60 DAT, mesmo o teor diminuindo após os 55 DAT, aproximadamente (Figura 4).

$\mathrm{O}$ acúmulo de B aumentou ao longo do ciclo, com maiores incrementos dos 50 aos 60 DAT, mesmo o teor diminuindo após os 55 DAT, aproximadamente. O acúmulo de $\mathrm{Cu}$ foi crescente ao longo do ciclo, com maiores incrementos dos 50 aos 60 DAT, mesmo o teor diminuindo após os 50 DAT. O acúmulo de Fe foi crescente ao longo do ciclo, com maiores incrementos dos 50 aos 70 DAT, assim como o teor cresceu ao longo do ciclo, tendo pequena queda no final. O acúmulo de Mn também foi crescente ao longo do ciclo, com maiores incrementos dos 50 aos 70 DAT, e teor diminuindo após os 60 DAT. O acúmulo de Zn foi crescente ao longo do ciclo, com maiores incrementos dos 50 aos 70 DAT, e teor crescente, com pequena queda a partir dos 50 DAT, até o fim do ciclo (Figura 4). Os macronutrientes foram absorvidos na seguinte ordem decrescente: $\mathrm{K}, \mathrm{N}, \mathrm{S}, \mathrm{P}, \mathrm{Mg}$ e Ca. E os micro foram: $\mathrm{Fe}, \mathrm{Zn}, \mathrm{B}, \mathrm{Mn}$ e $\mathrm{Cu}$ (Figura 5).

Segundo Homa et al. (1969), em trabalho realizado com couve-flor em vasos contendo sílica e irrigados com solução completa, encontraram as seguintes quantidades de macronutrientes na "cabeça" aos 123 dias, a partir da germinação, em mg por planta: K - 1261, N - 1205, P - 149, $\mathrm{S}-147, \mathrm{Mg}-98, \mathrm{Ca}-45$.

Homa et al. (1969), trabalhando com couve-flor em vasos preenchidos com sílica e irrigados com solução nutritiva completa, observaram que os macronutrientes absorvidos em maiores quantidades pela couve-flor são o K e o N, seguidos de Ca, S, Mg e P.

Em trabalho descrito por Kuramoto et al. (1981), com couve-flor conduzida em vasos contendo sílica, para obtenção de sintomas de deficiência de micronutrientes, verificaram que os nutrientes absorvidos em maior quantidade em ordem decrescente foram: Fe, $\mathrm{Zn}, \mathrm{Mn}, \mathrm{B}$, $\mathrm{Cu}$ e Mo.

$\mathrm{O}$ acúmulo dos macronutrientes na planta inteira cresceu linearmente, durante todo o ciclo da cultura, indicando que esses nutrientes são exigidos pela planta durante todo esse período e cada vez em maior quantidade, tendo um máximo acumulado de 1,87; 0,54; 
3,$75 ; 2 ; 0,42$ e $1,26 \mathrm{~g}$ por planta, respectivamente para $\mathrm{N}$, $\mathrm{P}, \mathrm{K}, \mathrm{Ca}, \mathrm{Mg}$ e S (Figura 5).

A maior demanda de micronutrientes aconteceu no período 40 a 70 DAT para Mn e Zn, e para B, Fe e Cu o acúmulo cresceu linearmente, durante todo o ciclo da cultura, indicando que esses nutrientes são exigidos pela planta durante todo esse período e cada vez em maior quantidade, tendo um máximo acumulado de 5,97; 0,67; 15,$28 ; 5,43$ e 8,12 mg por planta, respectivamente para B, $\mathrm{Cu}, \mathrm{Fe}, \mathrm{Mn}$ e Zn (Figura 5).

Com os resultados da taxa de crescimento relativo (TCR) (Tabela 1) da massa vegetal para os nutrientes, obteve-se o índice que descreve a Taxa de Absorção
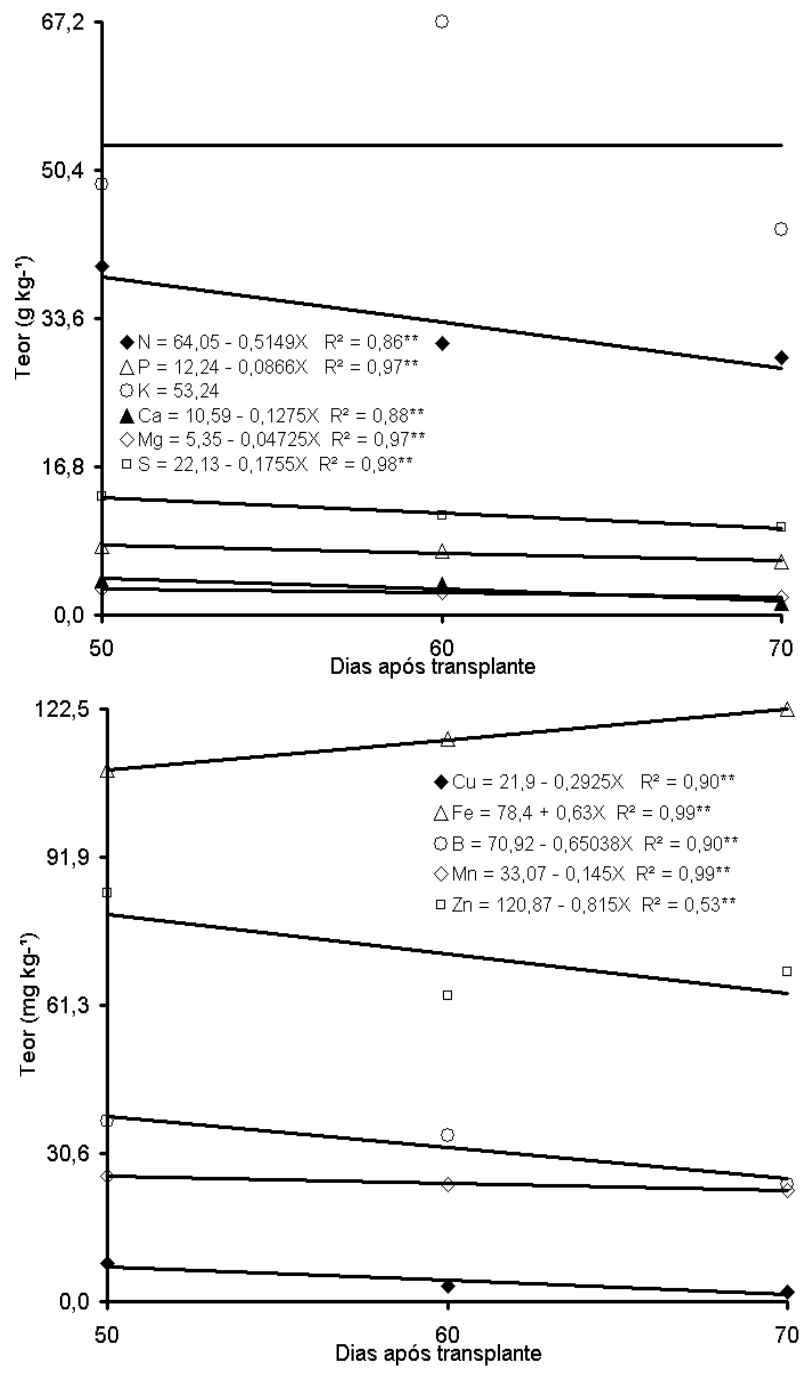

Figura 4 - Teor e acúmulo de macro e de micronutrientes na inflorescência de couve cultivada em substrato, Híbrido Verona, Jaboticabal-SP, UNESP, 2008.
Relativa de Nutriente (TARN) (Tabela 2) em toda a planta, ou o acúmulo em um órgão específico (TALON) (Tabelas 3, 4, 5 e 6), cujo resultado é expresso em quantidade absorvida ou acumulada do nutriente pelo material vegetal preexistente, durante um intervalo de tempo. Salienta-se que a TARN e a TALON dependem da massa vegetal produzida e de um fator intrínseco ao metabolismo vegetal, como a fotossíntese que está ligada às necessidades fisiológicas da planta.

A taxa de absorção dos macronutrientes (TARN) variou durante os dias após o transplante (Tabela 2). A taxa de absorção dos micronutrientes (TARN) variou em função do nutriente e do período de cultivo. Nota-se que
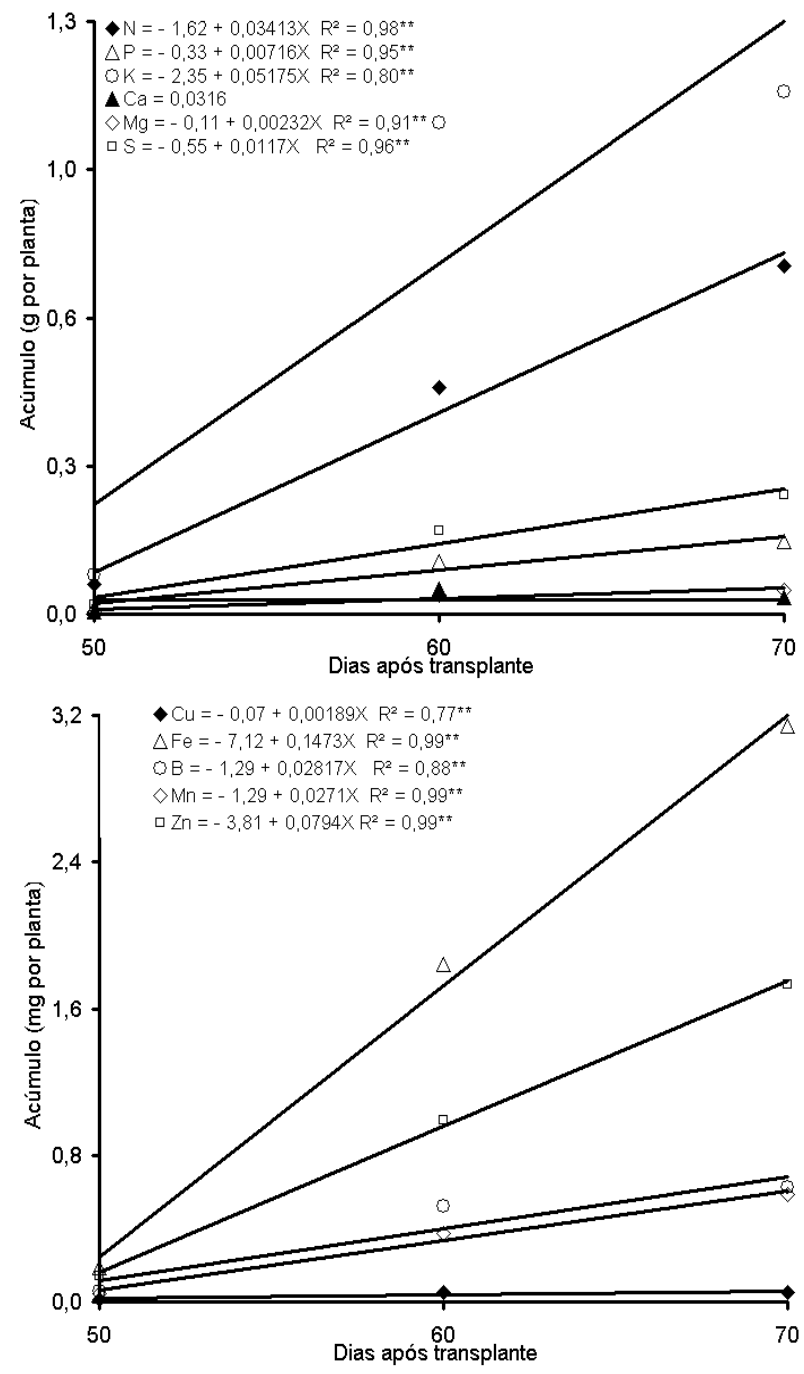

Ciênc. agrotec., Lavras, v. 35, n. 1, p. 45-55, jan./fev. 2011 
ALVES, A. U. et al.

a maior TARN para os micronutrientes variou entre $30-50$ dias após o transplante (Tabela 2).

A TALON dos macro e micronutrientes pela raiz, folhas, caule e inflorescência, das plantas de couve-flor, está apresentada nas Tabelas 3, 4, 5 e 6 nas quais se observa que as plantas de couve-flor apresentaram maior taxa de acumulação TALON, na inflorescência, exceto nos primeiros períodos em que este órgão não tinha surgindo. Nota-se, de maneira geral, que a maior taxa de acumulação TALON dos macro e micronutrientes ocorre no caule até aos 50 dias (Tabela 5), em seguida, a maior taxa ocorre na inflorescência (Tabela 6).

A TALON é o resultado dos processos que levam não apenas à acumulação, mas também à perda do nutriente para outros órgãos ou para o meio externo. Nos diversos órgãos da planta nem sempre a TALON acompanhou a TCR desses órgãos.
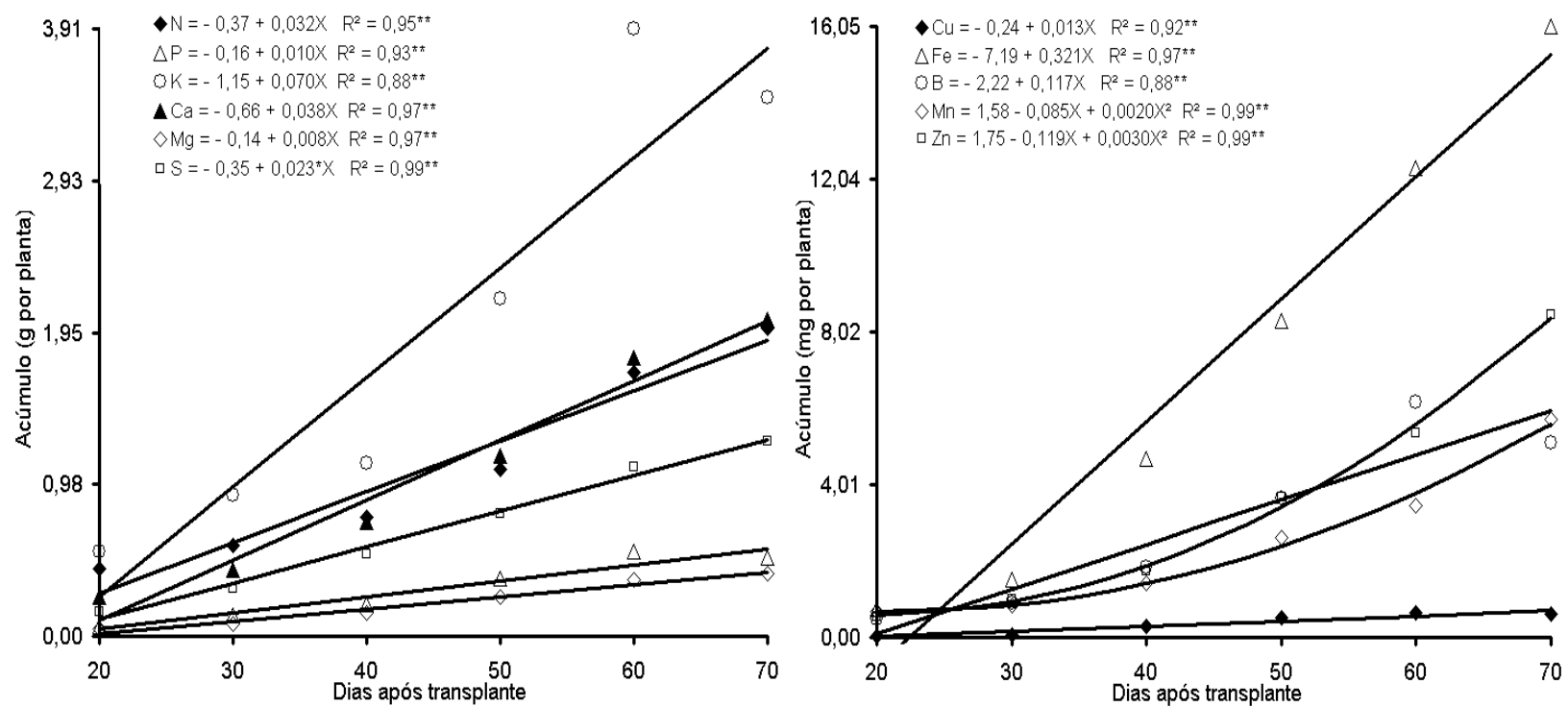

Figura 5 - Acúmulo de macro e de micronutrientes na planta inteira em couve-flor cultivada em substrato, Híbrido Verona, Jaboticabal-SP, UNESP, 2008.

Tabela 1 - Taxa de crescimento relativo nos órgãos das plantas de couve-flor cultivada em substrato.

\begin{tabular}{cccccc}
\hline \multirow{2}{*}{ Período (dias) } & Folha & Caule & Raiz & Inflorescência & Planta inteira \\
\cline { 2 - 6 } & & \multicolumn{5}{c}{$\mathrm{g} \mathrm{dia}^{-1}$ por planta } \\
\hline $20-30$ & 0,0525 & 0,0505 & 0,0623 & - & 0,0461 \\
$30-40$ & 0,0517 & 0,0387 & 0,0800 & - & 0,0602 \\
$40-50$ & 0,0344 & 0,0876 & 0,0329 & - & 0,0439 \\
$50-60$ & 0,0084 & 0,0196 & 0,0258 & 0,2291 & 0,0330 \\
$60-70$ & 0,0139 & 0,0227 & $-0,0159$ & 0,0475 & 0,0216 \\
\hline
\end{tabular}




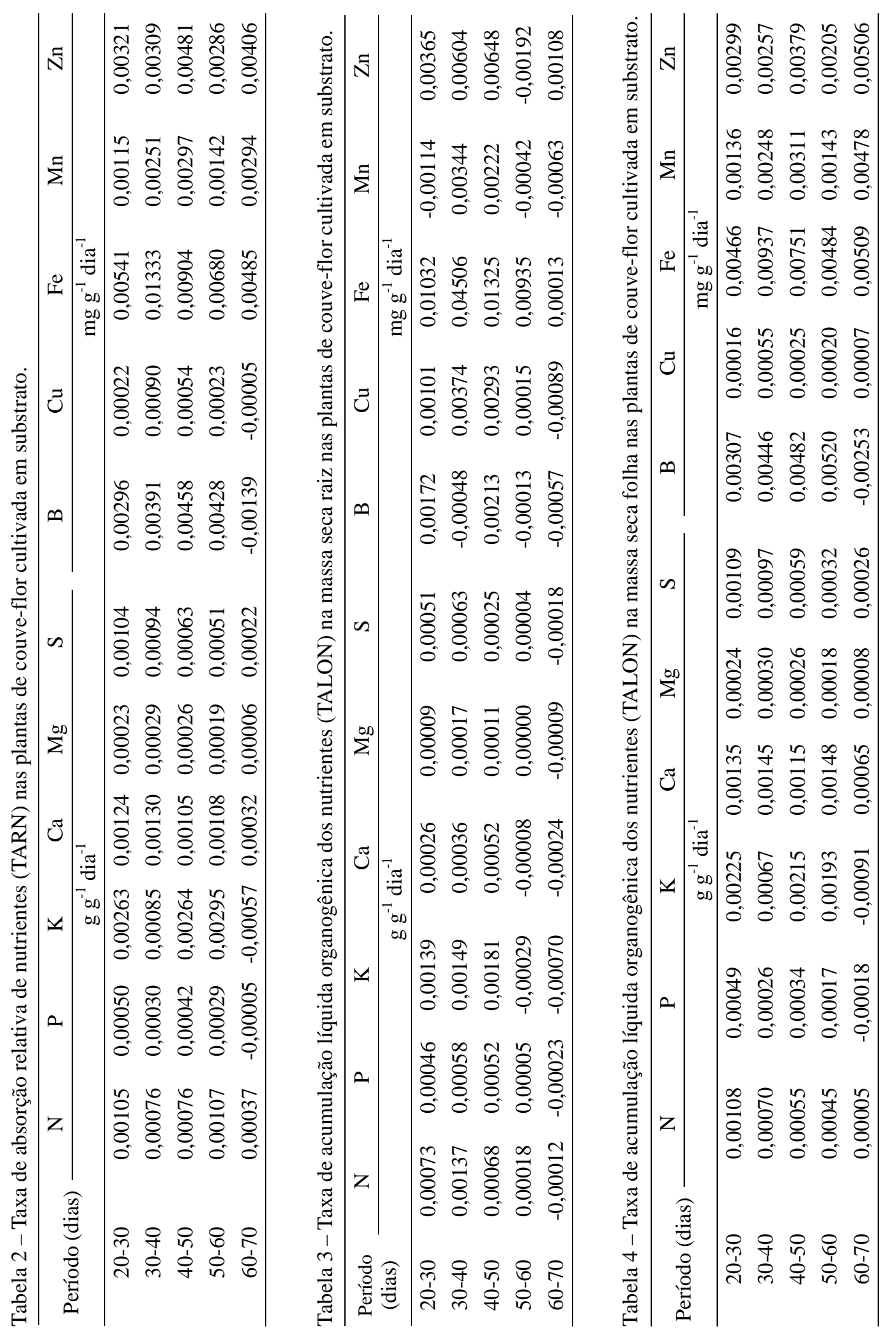



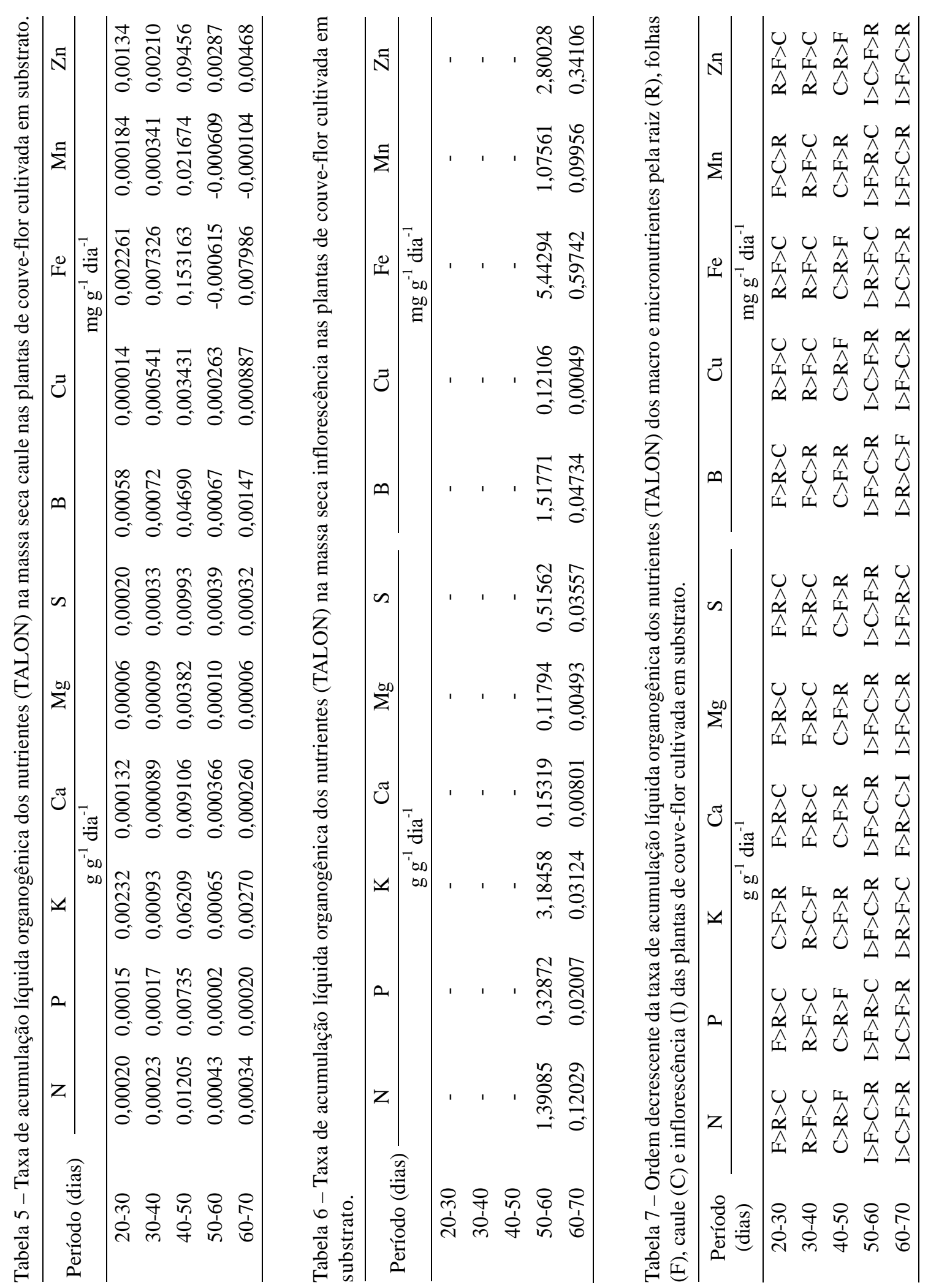

Ciênc. agrotec., Lavras, v. 35, n. 1, p. 45-55, jan./fev. 2011 


\section{CONCLUSÕES}

A maior demanda de nutriente aconteceu no período de 60 a 70 DAT para macro e micronutrientes, período que coincide com o desenvolvimento da inflorescência, tornando-se a fase de maior exigência nutricional;

A ordem decrescente dos manutrientes acumulados pela Couve-flor foi: $\mathrm{K}, \mathrm{N}, \mathrm{S}, \mathrm{P}, \mathrm{Mg}$ e $\mathrm{Ca}$ e os micro foram: $\mathrm{Fe}, \mathrm{Zn}, \mathrm{B}, \mathrm{Mn}$ e $\mathrm{Cu}$.

\section{AGRADECIMENTOS}

À FAPESP - Fundação de Amparo à Pesquisa do Estado de São Paulo, pelo auxílio à Pesquisa (Processo 2007/53241-4).

\section{REFERÊNCIAS BIBLIOGRÁFICAS}

BATAGLIA, O.C.; FURLANI, A.M.C.; TEIXEIRA, J.P.F.; FURLANI, P.R.; GALLO, J.R. Métodos de análise química de plantas. Campinas: Instituto Agronômico, 1983. 48p. (Boletim Técnico, 78).

GUPTA, U.C.; CHIPMAN, E.W.; MACKAY, D.C. Effects of molybdenum and lime on the yield and molybdenum concentration of crops grown on acid Aphagnum peat soil. Canadian Journal of Plant Science, Ottawa, v.58, n.4, p.983-992, 1978.
HOAGLAND, D.R.; ARNON, D.I. The water culture method for growing plants without soils. Berkeley: California Agricultural Experimental Station, 1950. 347p.

HOMA, P.M.; HAGG, H.P.; SARRUGE, J.R. Nutrição mineral de hortaliças: II., absorção de nutrientes pela cultura de couve-flor. O solo, Piracicaba, v.1, n.1, p.9-16, 1969.

KURAMOTO, M.; OLIVEIRA, G.D.C.; HAAG, H.P.; MINAMI, K. Deficiências de micronutrientes em couveflor. In: HAAG, H.P.; MINAMI, K. (Ed.). Nutrição mineral de hortaliças. Campinas, Fundação Cargill, 1981. p.117-130.

PIZETTA, L.C.; FERREIRA, M.E.; CRUZ, M.C.P. da; BARBOSA, J.C. Resposta de brócolis, couve-flor e repolho à adubação com boro em solo arenoso.

Horticultura Brasileira, Brasília, v.23, n.1, p.51-56, 2005.

RIBEIRO JÚNIOR, I.R. Análises estatísticas no SAEG. Viçosa, MG: UFV, 2001. 301p.

VIDIGAL, S.M.; PEREIRA, P.R.G.; PACHECO, D.D. Nutrição mineral e adubação da cebola. Informe Agropecuário, Belo Horizonte, v.23, n.218, p.36-50, 2002. 